Military Technical College Kobry El-Kobbah, Cairo, Egypt

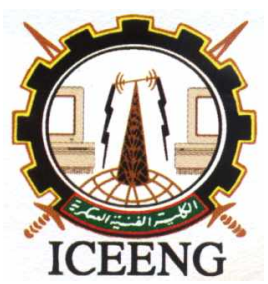

\section{Adaptive characteristic for compensated transmission lines with STATCOM}

\section{$6^{\text {th }}$ International Conference on Electrical Engineering ICEENG 2008}

By
A. N. Abdel-Latief*
A. F. Abdel-Gawad **
M. E. Mandour**
A.A. Ishak ***

\title{
Abstract:
}

Presence of a FACTS device like STATCOM in the transmission system improves system stability and enhances system voltage, but certain other problems emerge in the field of power system protection. In particular, transmission line protection. The implementation of control strategies for STATCOM introduces new power system dynamic problems that must be considered. This paper presents simulation results for investigation STATCOM impact on transient components of voltage and current during several types of faults.

* Egyptian Electricity Transmission Company -Egypt

** Faculty of Engineering- Zagazig University-Egypt

*** Faculty of Engineering -Benha University-Egypt 


\section{Introduction:}

With the ongoing growth of the electric power demand and deregulation in electrical power industry, numerous changes have been introduced to modern electricity industry. Transmission systems are now being pushed to their stability and thermal limits. In this respect, due to the recent advances in high power semiconductor technology, Flexible Alternating Current Transmission Systems (FACTS) technology has been proposed to solve this problem. Power flow through an AC line is function of the phase angle, line end voltage and line impedance. With FACTS devices, one can control the phase angle, the voltage magnitude at chosen buses and/or line impedance. A study consisted of three parts had been organized in [10] to give a brief description of Flexible AC Transmission Systems (FACTS) device operation and characteristics of Static Var Compensator (SVC) and Static Compensation STATCOM installed in mid point of the transmission line. The impact of STATCOM on distance relays have explored in [11], during single line to ground faults. The study indicated a distance relay was not the best protection for mid point compensated transmission line with shunt FACTS devices. Analytical and simulation results for investigating the operation of impedance based protection relays in a power system containing the STAT- COM had been presented in [5]. This paper investigates impact of the STATCOM on transient components of voltage and current during several types of faults. Then, the tripping boundary characteristics, which will be required in presence of STATCOM to adapt the relay settings, are also highlighted.

\section{STATCOM MODELING \&SIMULATION}

\section{A. STATCOM Principals}

The STATCOM is a shunt-connected solid-state synchronous voltage source, composed of a multi-pulse voltage sourced inverter and a dc capacitor, is shown schematically in Fig. 1. It can be considered, as a perfect voltage source behind a coupling reactance provided by the leakage inductance of the coupling transformer. The $\mathrm{V}-\mathrm{I}$ characteristic of the STATCOM is shown in Fig. 2. The STATCOM can provide both capacitive and inductive compensation and it is able to control its output current over the rated maximum capacitive or inductive range independently of the AC system voltage. That is, the STATCOM can provide full capacitive output current at any system voltage [6]. 


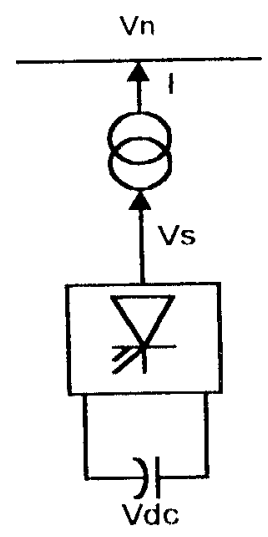

Fig. 1. Schematic Diagram for the STATCOM

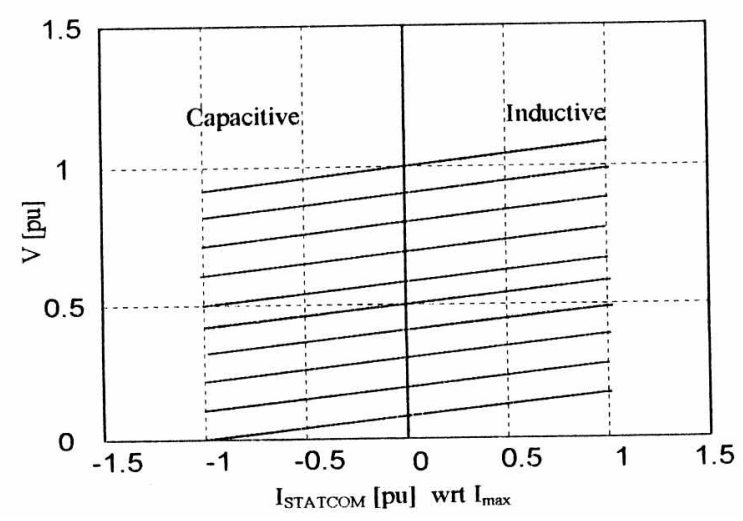

Fig.2. V-I Characteristics of the STAT COM

\section{B. STATCOM Simulation in Matlab}

48-Pulse GTO STATCOM model consists of three level GTO inverters in four sets to obtain three-phase voltages at the output, which are applied to the secondary windings of four transformers $15 \mathrm{KV} / 138 \mathrm{KV}$ - 40MVA. The fundamental components of voltages obtained on the $138 \mathrm{kV}$ sides of the transformers are added in phase by the serial connection of primary windings. The inverters use a nominal DC voltage $24 \mathrm{KV}$. The magnitude of square voltage can be $+\mathrm{V}_{\mathrm{dc}}, 0,-\mathrm{V}_{\mathrm{dc}}$. The 0 in each quarter cycle is defined as 'dead angle" $\lambda$ and it can be calculated, for 48 pulse inverter, as follows

$\lambda=\frac{\pi}{48}$

The fundamental component of voltage source inverter $V_{X}$ has the amplitude of

$V_{X}=\frac{2}{\pi} V_{D C} \cos \left(\frac{\pi}{24}\right) \cos \gamma$

The total capacitance of the DC link in farads, is related to the STATCOM rating and to the DC link nominal voltage. The energy stored in the capacitance (in joules) divided by the STATCOM rating (in VA) is a time duration which is usually a fraction of a cycle at nominal frequency. For the simulation data, $(C=1000 \mu \mathrm{F}, \mathrm{Vdc}=24000 \mathrm{~V}$, Snom=100 MVA), where

$t=\left(\frac{1}{2} \times C \times V^{2}\right) / S_{\text {nom }}$ 
The calculated time, $\mathrm{t}$ in (3) is $3.0 \mathrm{~ms}$, which represents 0.18 cycle for a $60 \mathrm{~Hz}$ frequency $[2,3]$.

\section{CASE STUDY}

\section{A. Power System Model}

The simulated model shown in Fig. 3 represents two $200 \mathrm{Km}$ parallel transmission lines connect two $138 \mathrm{KV}, 6500 \mathrm{MVA}$ generators at load angle $20^{\circ}$. The $100 \mathrm{MVA}, 48-$ pulse STATCOM is installed in the middle of second line to regulate its voltage to the reference voltage 1 p.u by generating or absorbing reactive power [11].

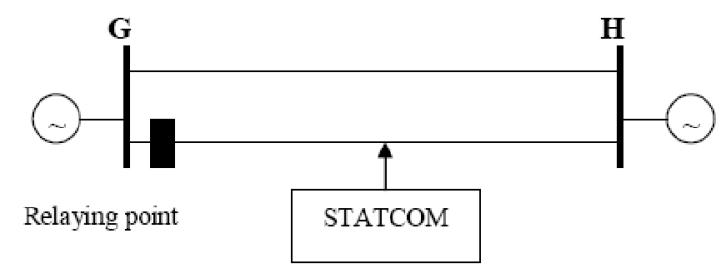

Fig. 3. A Single Line Diagram of the Sampled Network

\section{B. STATCOM Response during Faults}

In the system shown in Fig. 3 assume solidly earthed fault at phase R occurred on the right side of the STAT COM and the fault distance to the relaying point is $150 \mathrm{Km}$. The three phase currents, voltages and the STATCOM response during the specified fault condition are presented in Fig. 4.

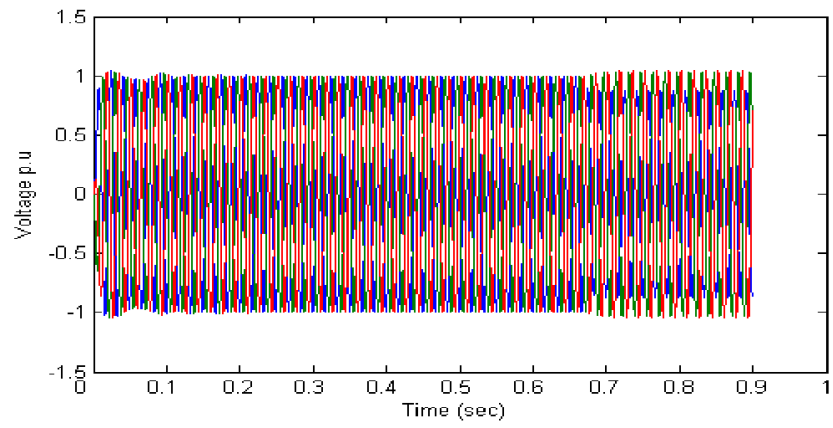

Fig. 4a. The Three-Phase Voltages

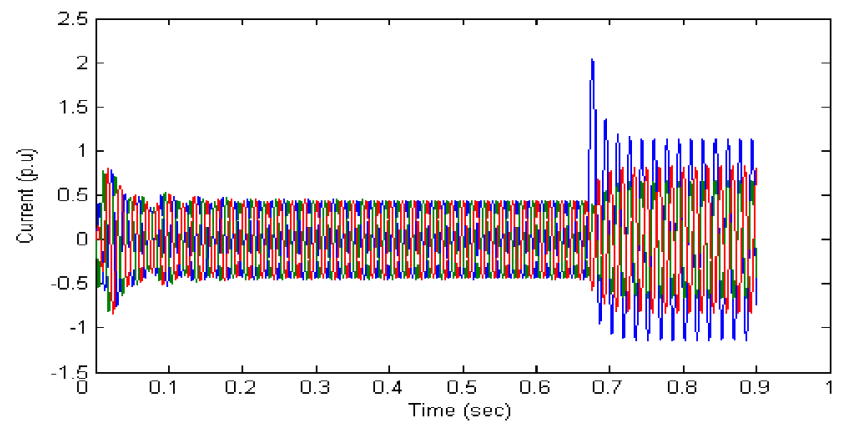

Fig. 4b. The Three-Phase Currents 


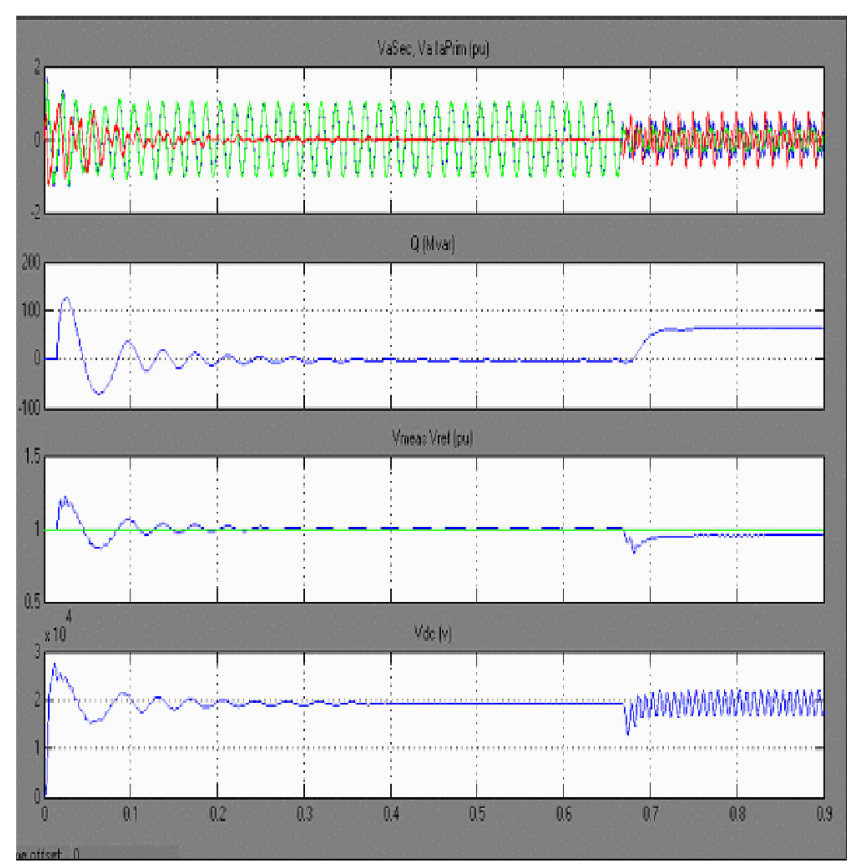

Fig.4c. The STATCOM Response

Fig. 4. The Simulated R-G Fault on the Right Side of STATCOM at $150 \mathrm{Km}$ away from Bus $\mathrm{G}$

The simulation results are shown in Fig. 4, in steady state, the connected bus voltage is the reference value so there is no need to inject reactive current in the network. But, during the fault condition, the STATCOM acts as a capacitor to compensate the connected bus voltage from 0.8 p.u to 0.92 p.u. There is an oscillatory increasing in the STATCOM dc capacitor voltage. In presence of the STATCOM, the faulty phase R experiences a severe under-voltage compared to the healthy phases, while the voltages of healthy phases S\&T experience over voltage. In addition, the currents in both faulty phase $\mathrm{R}$ and healthy phases S\&T obviously increase.

The same fault condition is repeated without installing the STATCOM device for comparing between three phase currents and voltages in two conditions, as shown in Fig. 5
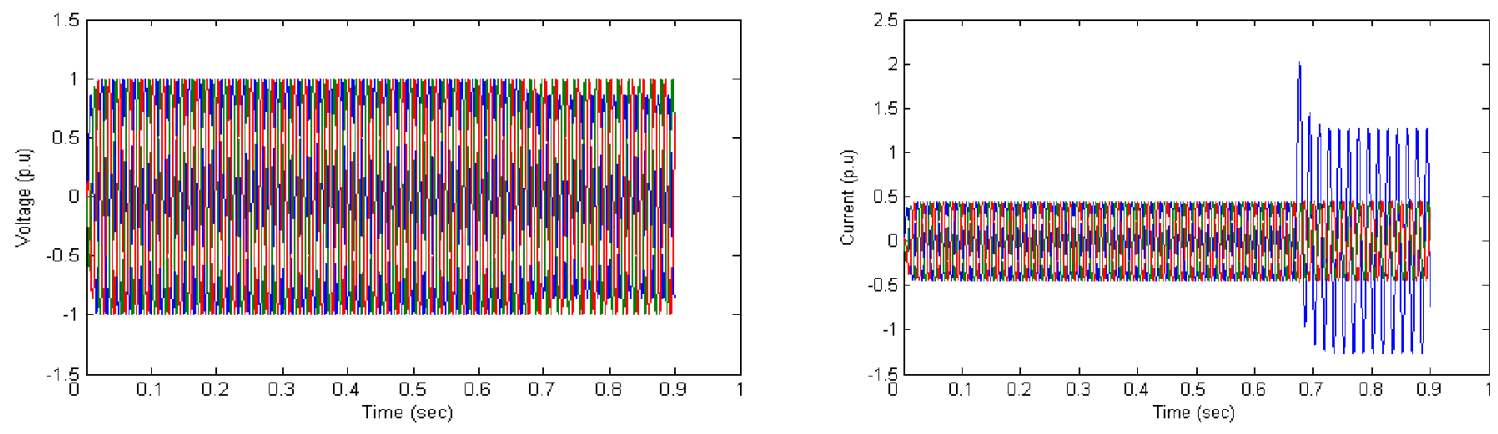

Fig. 5a. The Three-Phase Voltages

Fig. 5b. The Three-Phase Currents

Fig. 5. The Three Phase Voltages and Currents for a Simulated R-G Fault at $150 \mathrm{Km}$ without Installation of the STATCOM 
Without existence of the STATCOM, as shown in Fig.5 the faulty phase R only experiences a severe under-voltage compared to the healthy phases, with no changing in voltages of healthy phases S\&T. In addition, the current in faulty phase R only increases.

Assume another unsymmetrical fault type R-S is occurred on the right side of the STATCOM and the fault distance to the relay point is $150 \mathrm{Km}$. The three phase currents, voltages and the STATCOM response during the specified fault condition are presented in Fig. 6. It shows that, in steady state, the connected bus voltage is the reference value so there is no need to inject reactive current in the network. But, during the fault condition, the connected bus voltage increases from 0.64 p.u to 0.76 p.u in the same time, there are no measurements of the reactive power. In addition, there is an oscillation in the STATCOM dc capacitor voltage.

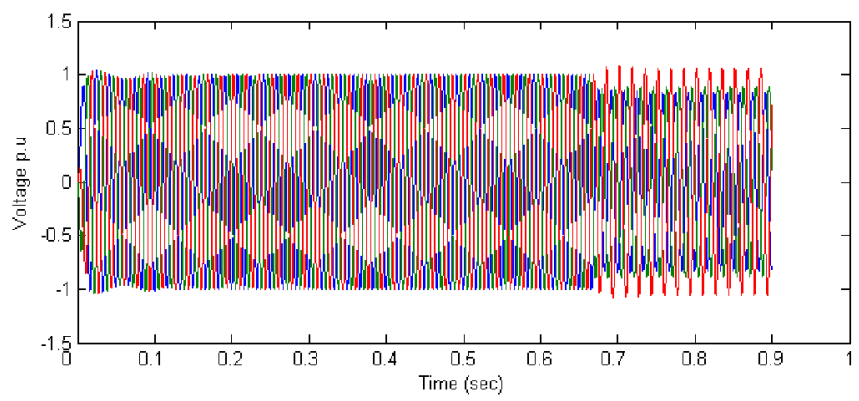

Fig. 6a. The Three-Phase Voltages

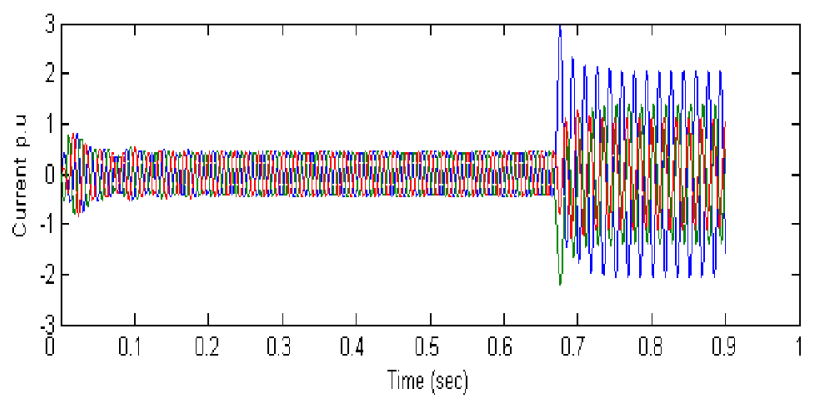

Fig. 6b. The Three-Phase Currents 


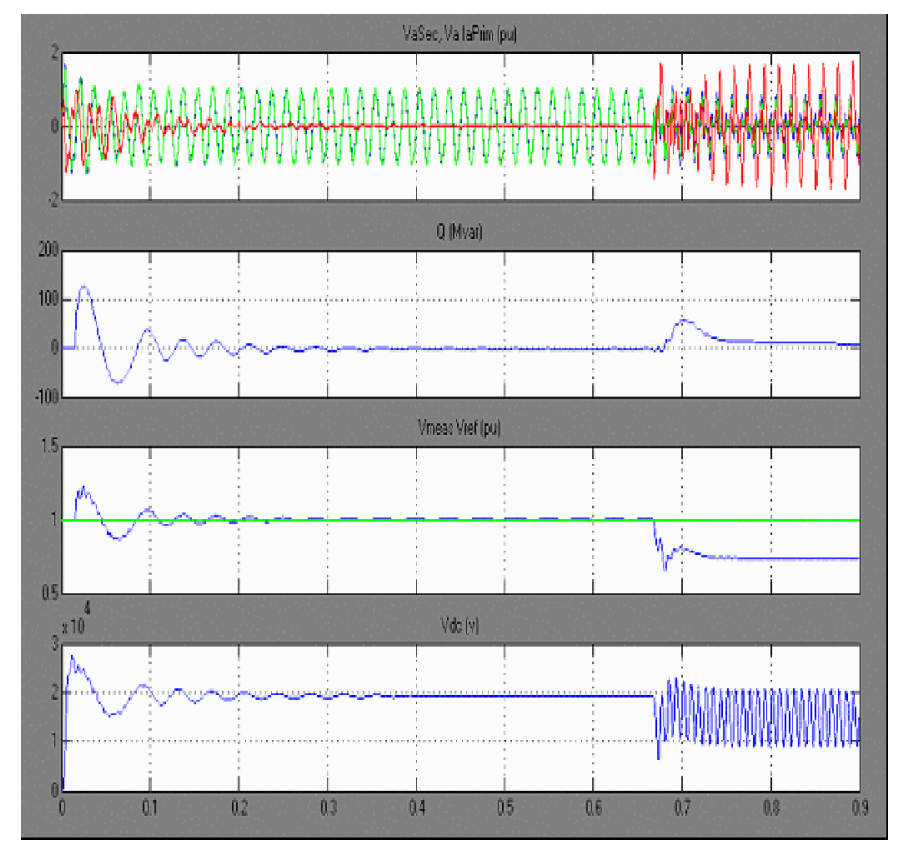

Fig. 6c. The STATCOM Response

Fig. 6. The Simulated R-S Fault on the Right Side of STATCOM at $150 \mathrm{Km}$ away from Bus G

In presence of the STATCOM, the faulty phases R\&S experience severe undervoltages compared to the healthy phase $T$, while the voltage of healthy phase experiences over voltage. In addition, the currents in both faulty phases R\&S and healthy phase T obviously increase with no ability to identify the faulty phases.

The same fault condition is repeated without installing STATCOM device, the three phase currents and voltages are presented in Fig.7

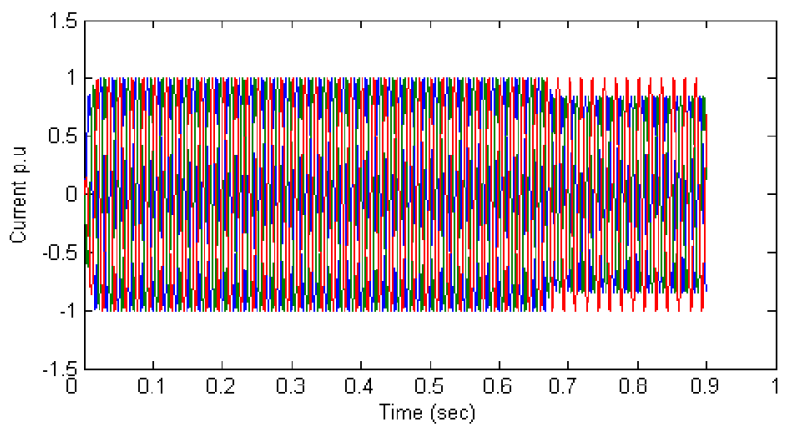

Fig. 7a. The Three-Phase Voltages 


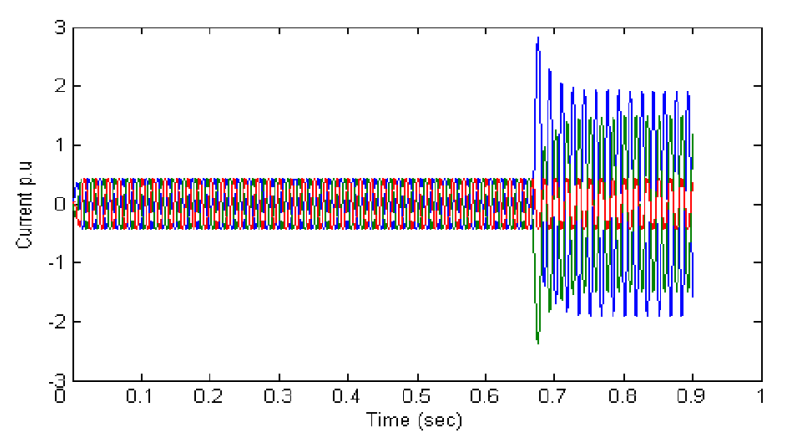

Fig. 7b. The Three-Phase Currents

Fig.7. The Three Phase Voltages and Currents for Simulated R-S Fault at Distance of $150 \mathrm{Km}$ without Installation of STATCOM

As seen in Fig.7 the faulty phases R\&S only experience undervoltages without changing in the voltage of healthy phase. With respect to the currents, the currents of the faulty phases only increased without any increasing in the current of the healthy phase.

The difference between the three phase currents and voltages with installing the STATCOM and without can be produced due to the STATCOM application. Where, the STATCOM are used to maintain the connected bus voltage in the reference value; a balanced three-phase firing is employed. STATCOM control system acts on a dc voltage equivalent to three-phase voltages. Thus for unsymmetrical faults, in which faulty phases experience a severe under-voltage compared to the healthy phases, the STATCOM will provide equal compensation for all the three phases. The STATCOM measuring system computes the positive-sequence components of the STATCOM voltage and current [3], this will in turn result in a reduced compensation, as the equivalent voltage will not be a true representation of the faulted phase. In addition, the healthy phase(s) voltages can increase due to this equal compensation. In addition, the overcompensation of the healthy phases can result in an increased reactive current in healthy phases. This increases the possibility of incorrect phase selection.

The oscillations in the STATCOM dc capacitor voltage, due to presence of negative sequence in the ac system, which causes second harmonic oscillations in the dc capacitor voltage. This disturbance on the dc capacitor voltage results in a third harmonic introduced in the ac system $[4,7]$. It is worth to note that, the measurement of the reactive power in Matlab Software is valid only for a balanced and harmonic free system [3].

\section{THE TRIPPING BOUNDARIES}

\section{A. Single line to ground faults}

The simulated system, at a certain operation condition, transfer angle between the two sources is kept, constant $\delta=20^{\circ}$, the single line to ground fault (R-G) occurs in different location (0-95\% of line length) and different fault resistance $\mathrm{R}_{\mathrm{f} \text {. }}$ to cover all possible ranges of fault resistance, $(0-50 \Omega)$ to plot the ideal tripping characteristics with and without the STATCOM, as shown in Fig.8. When the STATCOM is present at the midpoint of the line both of apparent resistance and reactance increase for fault 
resistance $R_{F}=0 \Omega$, also, with increasing the value of fault resistance to $50 \Omega$ both apparent resistance and reactance increase. This is due to operation of STATCOM to maintain the midpoint voltage to its normal on the other words, under the fault condition the voltage at the midpoint dips from its nominal voltage. This requires the STATCOM to produce more reactive current to boost the voltage at the midpoint and thus increase the apprent reactance. Increasing of the reactive current related to absorbing real power to charge the capacitor thus increases the apprent resistance. Another point must be taken into account, when the fault is further away from the relay, the injected current is reduced but it is observed, the apparent resistance and reactance increase due to varation in line parameters.

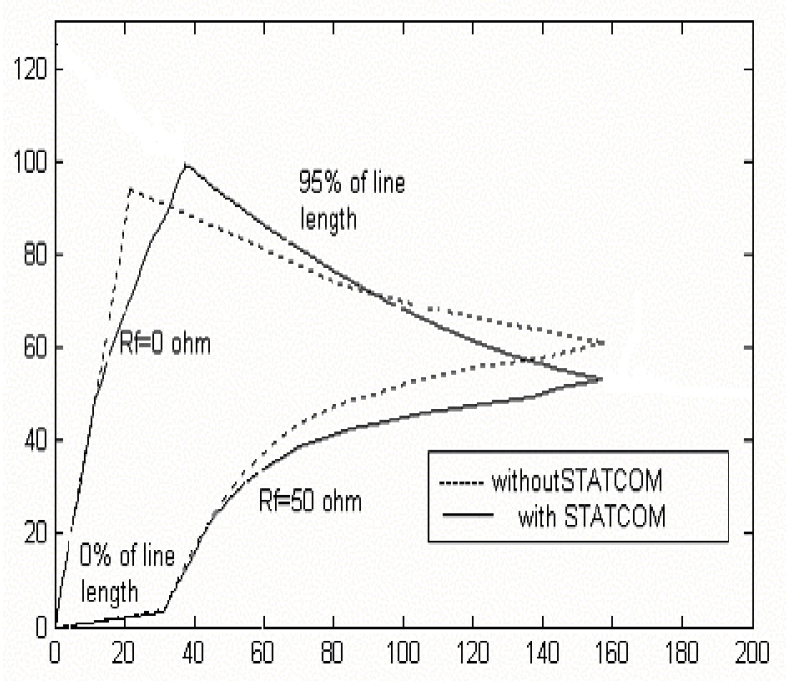

Fig.8. A Comparison between the Ideal Tripping Characteristics with and without the STATCOM for Single Line

\section{B. Line to line faults}

Fig.9 presents a comparison between the characteristic in presence of the STATCOM at the midpoint and without for line-to-line fault conditions. As similar to the previous condition (phase to ground fault), the system operating conditions are kept constant and the fault location in $\mathrm{Km}$ (from 0-95\% of line length) and fault resistance $\mathrm{R}_{\mathrm{f}}$ (from 0-10 $\Omega)$ are varied to give the trip characteristic with and without installation of the STATCOM.

For line-to-line faults R-S, the apparent reactance increases because of injection of the reactive power, but unlike the single line to ground fault, the apprent resistance decreses. The reason can be explained as the voltage drop is increased in case of line to line faults, whereas the dc capacitor is charged more than the STATCOM rated value therefore the capacitor discharge until the voltage drop between the STATCOM output voltage and the connected bus voltage equal to the rated value of STATCOM.

The dynamic of variation of the dc voltage related to temporary variation in STATCOM voltage phase shift lead produces a temporary flow of active power which 
results in an decrease of capacitor voltages. When the fault is further away from the relay the voltage drop decreased so the flow of active power also decreased until a certain location where the DC capacitor absorb active power from the network to be chareged.

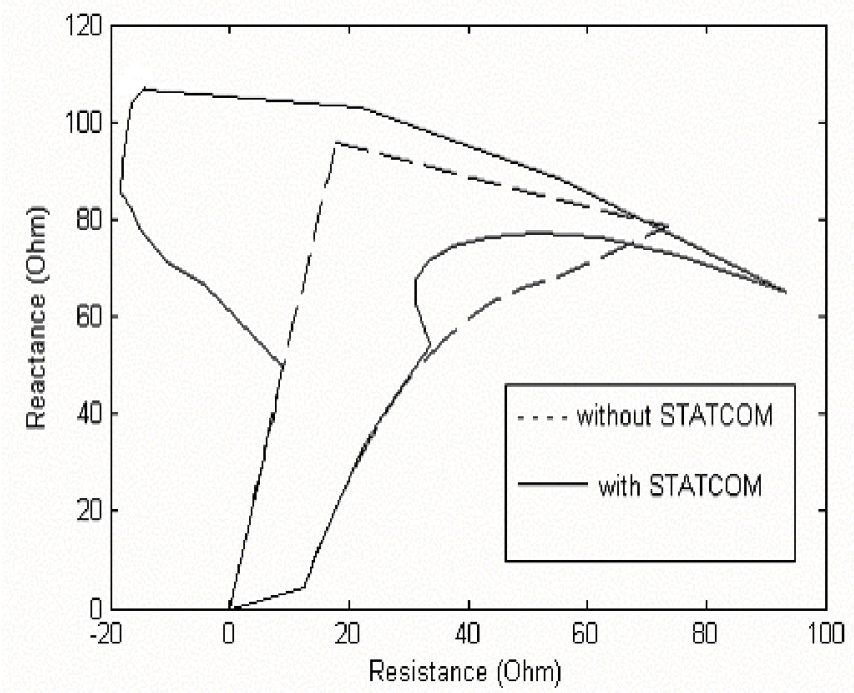

Fig. 9. A Comparison between the Ideal Tripping Characteristics with and without STATCOM for R-S Fault

It is observed from Figures $8 \& 9$, the fault occurrence in the left side of STATCOM, the tripping characteristics for both single line to ground faults and line to line fault are identical similar to the characteristic without presence of the STATCOM.

\section{CONCLUSIONS}

Based on variety of computer simulation results, the dynamic variations of both reactance and resistance measured during several types of fault in presence of the STATCOM have been discussed in details. Then a comparision between the ideal tripping charactrisitcs with and without presence of the STATCOM at the midpoint of line are illustrated for both of single line to ground and line-to-line faults. The resulted trip characteristics clearly demonstrate that the area under the trip boundary changes with change of the STATCOM operating conditions due to changing of the fault conditions. So, The resulted tripping boundaries indicate importance of using Artificial Neural Network based protection scheme in compensated lines with STATCOM. 


\section{REFERENCES}

[1] "Digital Protection for Power Systems", T. Jones and S. K. Salman,, IEE Power series 15, (OPeter peregrinus Ltd. On the behalf of the institute of Electrical Engineers, London, United Kingdom, 1995.

[2] C.Schauder, E.Staccy, M.Lund, A.Keri, A. Mchraban and A.Edris," AEP, UPFC Project: Installation, Commissioning and Operation of The \pm 160 MVA STATC (Phase I), IEEE transactions on Power delivery, No. 13, No. 4, pp.1530-1534, October 1998.

[3] Dynamic System Simulation For MATLAB ,SIMULINK, Copyright 1990-2000, The Math. Works, Inc.

[4] S. Chen, G. Joos, L.T. Moran," Dynamic Performance of PWM Statcoms Operation Under Unbalance and Fault Conditions In Distribution Systems", IEEE transactions on Power delivery, No. 1, pp.950-955, 2001.

[5] K. El-Arroudi, G. Joos, and D. T. McGillis, "Operation of Impedance Protection Relays with the STATCOM”, IEEE PWRD, Vol. 17, No.2, pp. 381-387, April. 2002

[6] "Thyristor Based FACTS Controllers for Electrical Transmission Systems", R. M. Mathur, R. K. Varma, IEEE press, Wiley \& sons INC. publication, 2002.

[7] C. A.Cavaliere, E.H.Watanabe and M.Aredes, "Multi-pulse STATCOM Operation Under Unbalanced Voltages", IEEE transactions on Power delivery, pp. 567-572, 2002.

[8] M. Khederzadeh," Power Quality Impacts of Series and Shunt Compensated Lines on Digital Protective Relays", international conference on power system transients, IPST, New Orleans, USA, 2003.

[9] C. Dufour, J. Belanger, "Real Time Simulation of a 48-Pulse GTO STATCOM Compensated Power System on a Dual-Xeon PC Using RT-LAB", the international conference on power systems transients (IPST'05), No.05, Montreal, Canda, 19-23 June 2005.

[10] T. S. Sidhu, R.K.Varma, F. A. Albasri, " Performance of Distance Relay on Shunt FACTS Compensated Transmission Lines", IEEE transactions on Power delivery, Vol 20, No. 3, pp.1837-1845, July 2005.

[11] X. Y. Zhou, H.F.Wang, R.K. Aggarwal and P.Beaumont, " The Impact of STATCOM on Distance Relay", 15 ${ }^{\text {th }}$ PSCC,Liege, 22-26 August 2005. 